\title{
Current hypospadias management: Diagnosis, surgical management, and long-term patient-centred outcomes
}

\author{
Melise A. Keays, $M D^{\prime \prime}$ Sumit Dave, $M D^{2}$ \\ 'Division of Urology, Department of Surgery, Children's Hospital of Eastern Ontario, University of Ottawa, Ottawa, ON, Canada; 2Division of Urology, Department of Surgery and Pediatrics, London Health \\ Sciences Centre, London, ON, Canada
}

Cite as: Can Urol Assoc J 2017;11(1-2Suppl1):S48-53. http://dx.doi.org/10.5489/cuaj.4386

See related commentary on page S54.

\section{Abstract}

In this article, we present the current approach to hypospadias, a review of the classification, preoperative evaluation, and factors that enable decision-making during surgery. We will then discuss patient-reported outcomes, evaluating the patients' and parents' perspectives regarding hypospadias repair.

\section{Introduction}

Hypospadias, a condition where the urethra opens on the underside of the penis with associated ventral penile curvature, is the second most common genital birth defect in boys, following cryptorchidism. With an incidence of one in 200 live male births, hypospadias correction is one of the common surgical procedures performed by pediatric urologists. ${ }^{1,2}$

\section{Classification}

The initial diagnosis of hypospadias is typically made after birth during physical exam, where boys with hypospadias are found to have a ventral skin deficiency with a dorsal hood of foreskin and an abnormally located meatus with varying degrees of ventral penile curvature. The standard classification of hypospadias is based on location of the urethral meatus: distal, midshaft, or proximal (Fig. 1). This classification system is misleading, as some variants of distal hypospadias are associated with proximal spongiosal hypoplasia and penile curvature, which may require a more involved surgical reconstruction, while some apparent severe cases of proximal hypospadias present less of a surgical challenge when favourable anatomy is present.
Another form of distal hypospadias is termed megameatus intact prepuce variant, which is usually discovered when the foreskin becomes retractable or during a newborn circumcision. The meatus is widely open and extends proximally to the level of the corona. As universally recommended for hypospadias, circumcision should be deferred, although evidence suggests that surgical outcomes are comparable in circumcised penises with a distal hypospadias using the tubularized incised plate (TIP) repair. ${ }^{3,4}$

In cases of proximal hypospadias associated with unilateral or bilateral non-palpable cryptorchidism, disorders of sexual differentiation are noted in $17-29 \%$ of patients. ${ }^{5-7}$ Therefore, initial evaluation should include serum electrolytes, 17-hydroxyprogesterone (17-OHP), karyotype, abdominal ultrasound to assess for Mullerian structures, and endocrine referral.

\section{Surgical management}

The surgical management of hypospadias aims to achieve:

1. A straight penis with a slit-shaped and adequate caliber meatus at the apex of the glans

2. A conical reconfigured glans

3. Either a circumcised appearance of the penis or if the parents opt for preputial reconstruction, a foreskin that is complete circumferentially and easily retractable

4. An acceptable cosmetic outcome judged objectively

The multiple surgical options available for hypospadias repair are a testament to the fact that no surgical procedure guarantees universal success by all surgeons. As is true for all reconstructive procedures, the best chance of a good outcome is with the first operation. ${ }^{8}$ All hypospadias surgery, even for an innocuous-appearing distal hypospadias, must, therefore, not be considered a minor procedure. The position of the meatus is not the sole determinant of the difficulty in reconstruction. Distal hypospadias can be associated with a more technically demanding repair due to small glans size, poor quality of the urethral plate, proximal spongiosal 


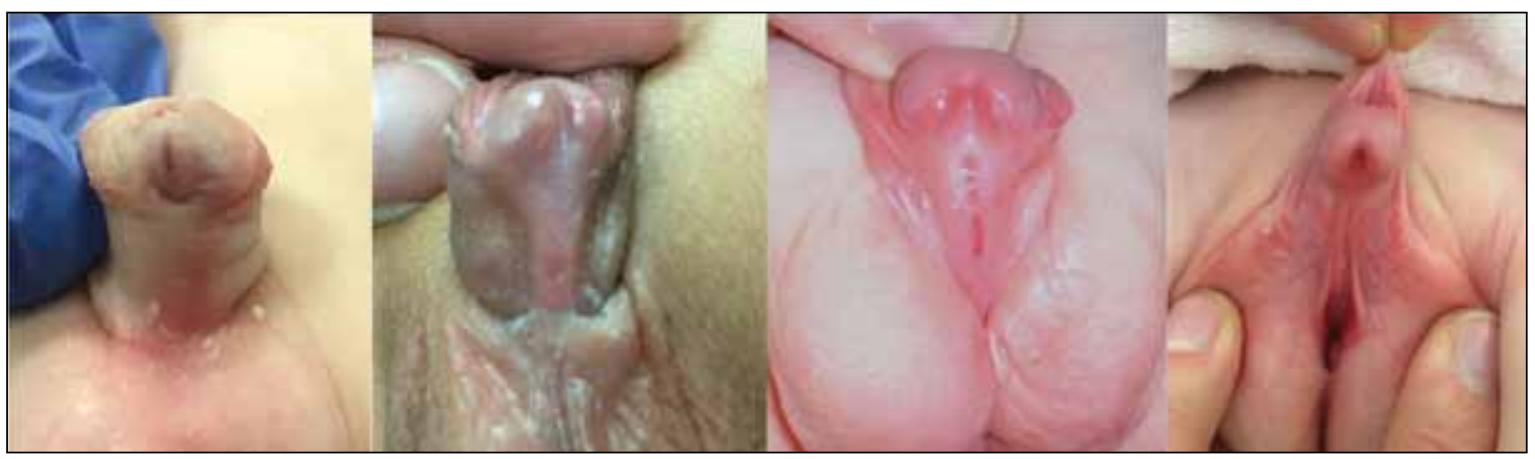

Fig. 1. Increasing severity of hypospadias (left to right): distal (sub-coronal); midshaft (skin tethering); penoscrotal; and perineal.

hypoplasia, and possible ventral curvature (VC). Therefore, all hypospadias surgery should preferably be performed by a competent hypospadiologist, who ideally has an annual hypospadias surgical volume of $40-50$ cases. $^{9}$

\section{Preoperative considerations}

The physical examination of a child with hypospadias yields key information that allows operative planning. ${ }^{10,11}$

1. Location of the meatus and the degree of proximal spongiosal hypoplasia

2. Presence and degree of VC

3. Quality (width and depth) of the urethral plate

4. Size of the glans and the depth of the navicular fossa

5. Degree of ventral skin deficiency

6. Scrotal abnormalities like penoscrotal transposition and bifid scrotum

7. Availability of the foreskin

8. Penile length

\section{Role of preoperative androgen therapy}

Preoperative androgen stimulation in the form of systemic testosterone, topical testosterone, and derivatives like dihydrotestosterone (DHT) and human chorionic gonadotropin (hCG) have been used to stimulate glans size preoperatively to allow better tubularization of the urethral plate and decrease the incidence of glans dehiscenc. ${ }^{12}$ Currently, there are no defined guidelines for recommending androgen use, nor a defined regimen. ${ }^{13,14}$ There is concern regarding the negative impacts of testosterone on wound-healing and increased bleeding during surgery. ${ }^{15,16}$ In addition, the impact of preoperative androgen use on decreasing the incidence of glans dehiscence has not been conclusively proven. ${ }^{17}$ A systematic review looking at preoperative therapy found significant heterogeneity in terms of the drug used, dosage, and evaluation of results or hypospadias outcomes..$^{18}$ Despite a lack of high-quality evidence to support that testosterone supplementation improves outcomes, it remains a widely used practice reported by $78 \%$ of practicing urologists. ${ }^{19}$ Therapy must be stopped $1-2$ months prior to surgery to avoid adverse effects during or after surgery. ${ }^{20}$

\section{Timing of surgery}

Surgical intervention for hypospadias can be performed at any age, however, most authors recommend operative intervention at 6-18 months. ${ }^{9}$ The American Academy of Pediatrics suggests this time interval to limit psychological stress and subsequent behavioural problems seen in toddlers undergoing genital surgery. ${ }^{21}$ There are conflicting reports regarding whether increasing age at surgery leads to a higher complication rate. ${ }^{22,23}$

\section{Operative principles}

The operative steps of hypospadias surgery involve penile degloving, correction of VC (orthoplasty), reconstruction of the urethra (urethroplasty), providing a vascularized coverage for the urethroplasty, reconstruction of the glans (glansplasty), and finally a cosmetic skin coverage to create a circumcised penile appearance. The key surgical principles to achieve optimal surgical outcomes include the use of magnification, fine instruments and sutures, minimal and atraumatic tissue-handling, careful hemostasis, and good surgical assistance. ${ }^{9,11}$

Most surgeons perform stented repairs, although distal hypospadias repairs can be done without the use of stents. ${ }^{24}$ There is no uniform consensus regarding dressings ${ }^{25}$ and use of prophylactic antibiotics. ${ }^{26,27}$ Surgeon preference often dictates these variables. Most hypospadias surgery is performed as an outpatient and caudal or dorsal penile nerve blocks are used for postoperative analgesia. There is ongoing controversy whether caudal blocks lead to a higher incidence of urethral fistulas, although the evidence is of poor quality and needs confirmation. ${ }^{28}$

\section{Correction of ventral penile curvature}

Correction of VC is a key component of hypospadias surgery to achieve a straight penis, while preserving penile length and erectile function. VC is assessed preoperatively, but the surgical decision regarding the method of VC correction is made after penile degloving. ${ }^{11,20}$ 
Keays et al.

The steps of VC correction involve:

1. Penile degloving to the penopubic and penoscrotal junction with release of all penoscrotal tethering bands

2. Release of the glans wings and hypoplastic spongiosum from the corporal bodies

3. Dorsal plication using the Baskin modification of the Nesbitt procedure ${ }^{29}$

4. Proximal dissection of the spongiosum and distal division of the urethral plate ${ }^{30}$

5. Multiple fairy cuts to incise through the fibrotic spongiosal tissue without entering the corporal bodies ${ }^{31}$

6. Corporotomy to incise through the tunica of the corpora cavernosum from the 3-9 o'clock position, elevating the tunica to create an ellipsoid defect (lengthening the ventral penile length) and coverage using dermal grafts, small intestinal submucosa (SIS), or a vascularized tunica vaginalis flap from the testes ${ }^{32}$

VC below $15^{\circ}$ degrees usually does not require any correction. VC between $15-30^{\circ}$ can be managed with dorsal plication, while curvature greater than $30^{\circ}$ may require more extensive maneuvers like urethral plate transection. The move towards ventral reconstruction with higher degrees of curvature is guided by the concern that dorsal plication shortens penile length and is associated with higher rates of recurrent curvature compared to ventral correction in boys with a $>30^{\circ}$ curvature. ${ }^{33}$

\section{Surgical options for urethroplasty}

There are multiple surgical options and several proposed algorithms to guide urethroplasty decision-making. ${ }^{34}$ Current practices appear to suggest that procedure selection is often guided by surgeon experience. Ongoing efforts to prospectively track surgical outcomes will hopefully lead to more standardized, evidence-based hypospadias decision-making. Surgical procedures can be divided into one- or two-stage procedures and into procedures that involve urethral plate (UP) tubularization, UP augmentation, and UP replacement.

\section{UP tubularization}

This urethroplasty technique comprises several procedures that involve tubularization of the UP distal to the hypospadic meatus. The Thiersch Duplay technique ${ }^{35}$ and the glanular approximation procedure (GAP) procedure ${ }^{36}$ involve simple tubularization of the UP after lateral incisions circumscribing the meatus. The TIP procedure proposed by Snodgrass in 1994 involves a midline incision of the UP to widen it and achieve a better caliber urethra, which is then tubularized. ${ }^{37}$ The superior cosmetic results and the low incidence of complications has led to wide consensus that the TIP urethroplasty is the most commonly used technique for distal hypospadias. ${ }^{38}$ An alternative technique, which discards the distal UP and relies on urethral mobilization to bring the meatus to an acceptable location, involves dissection of the urethra proximally to allow an advancement of the meatus to the glans. ${ }^{39}$ This procedure obviates potential complications, such as urethrocutaneous fistula, but achieves limited advancement even after extensive proximal mobilization..$^{39,40}$

\section{UP augmentation}

Snodgrass et al, who devised the TIP procedure, have shown that UP width does not impact results of tubularization using the TIP technique. ${ }^{41}$ However, alternative UP augmentation techniques have been used selectively in cases with poor UP quality. An inner preputial free graft, referred to as a "Snodgraft" 42 procedure places a preputial inlay graft on the incised surface of the UP with the premise that a graft covering a deep UP incision would decrease scarring. The Mathieu procedure flips a rectangular piece of foreskin distally, which is sutured to the edges of the UP on either side as an onlay flap to the UP. ${ }^{43}$ A transverse island flap, described by Asopa and Duckett, is derived from the dorsal preputial hood and can also be translocated ventrally to provide an onlay flap to augment the UP. ${ }^{44,45}$ Several studies with blinded raters have found superior cosmetic outcomes for TIP compared to Mathieu or onlays. ${ }^{46,47}$

\section{UP replacement}

In the presence of significant $\mathrm{VC}$, a proximal hypospadias, and a poor UP, urethral transection may be required, thereby, precluding the use of UP tubularization. There are several management options for urethroplasty in this situation. Most surgeons prefer to perform a two-stage urethroplasty with an initial preputial graft placement or a Byars flap followed by a second stage tubularization after six months. Alternative options include the Koyanagi repair and its modifications or a composite repair involving tubularization proximally and distally with a transverse preputial flap onlay in the middle.

\section{Outcomes}

\section{Distal hypospadias}

The outcomes of distal hypospadias repair are favourable, with a low incidence of redo surgery, but complications are encountered in 5-10\% cases. The TIP procedure has been well studied, with several authors showing consistently favourable results. ${ }^{48} \mathrm{~A}$ systematic review of outcomes of the TIP urethroplasty and the Mathieu procedure for distal hypospadias showed a lower fistula rate in the TIP group $3.8 \%$ vs. $5.3 \%$ ) and a lower stenosis rate in the Mathieu group 
$(0.7 \%$ vs. $3.1 \%) .{ }^{49}$ The use of dartos coverage and stents was associated with lower complication rates in this review.

\section{Proximal hypospadias}

Complication rates for proximal hypospadias with severe curvature show a high and variable complication rate of $15-56 \% .^{50,51}$ A systematic review comparing TIP to onlay preputial flaps for proximal hypospadias without significant VC showed no significant difference in urethroplasty complication rates. ${ }^{52}$ The Koyanagi repair has shown favourable results for proximal hypospadias, with a $17 \%$ complication rate in a series of 151 proximal hypospadias children. ${ }^{53}$ Two-stage repairs for proximal hypospadias repair in boys with $>30^{\circ}$ VC provides a reliable and reproducible option for success, although the evidence for this approach is weak. The use of preoperative androgen stimulation, tunica vaginalis flap coverage of the repair, and extended glans wings dissection are other factors presumed to decrease complication rates.

\section{Complications}

Postoperative complications can usually be identified early on in the first few months after surgery in most cases, but long-term followup is mandatory because delayed presentation with a urethral fistula and recurrent curvature of the penis following puberty spurt have been documented. ${ }^{9}$ Postoperative assessments may include observed voiding and post-void residue assessments or formal uroflowmetry.

The common complications following hypospadias repair include:

1. Urethrocutaneous fistula

2. Meatal stenosis

3. Urethral stenosis

4. Glans dehiscence

5. Urethral diverticulum or urethrocele, which can lead to infections and post-void dribbling

6. Cosmetic issues: Excess residual skin, skin tags, inclusion cysts, skin bridges, suture tracts

7. Hair-bearing urethra

8. Recurrent or persistent penile curvature

9. Spraying or misdirected urinary stream and/or irritative symptoms

10. Erectile dysfunction

11. Balanitis xerotica obliterans of the urethra leading to strictures

\section{Management of complications}

The management of hypospadias repair complications are performed after a period of healing over 4-6 months, with the exception of urethral or meatal stenosis, which require more emergent attention. Urethral fistula closures involve excision and closure of the fistula with adequate dartos flap coverage after excluding distal urethral stenosis. Coronal or more distal fistulas may also require a redo glansplasty. Symptomatic meatal stenosis will often require a dilatation or a meatotomy. Glans dehiscence can be managed with reoperative glansplasty. When a redo urethroplasty is required, the degree of postoperative scarring and the possibility of balanitis xerotica obliterans (BXO) may dictate reoperative management. A redo TIP procedure can be a viable option in the presence of a non-scarred urethral plate or primary glans dehiscence. ${ }^{54}$ In the absence of dorsal preputial tissue, a buccal graft harvested from the lip or cheek can be used to perform a staged redo procedure for more scarred or proximal repairs.

\section{Functional outcomes after hypospadias repair}

The majority of hypospadias outcome papers focus on surgical complications and there are few publications assessing long-term functional outcomes. A recent systematic review of the long-term functional outcomes following hypospadias repair demonstrated that patient reported urinary symptoms, such as obstructive voiding, spraying, and deviated stream, more often than controls. ${ }^{55}$ Obstructive flow based on evaluation of Qmax lower than the $95^{\text {th }}$ percentile was found in $13.5 \%$ of patients compared to $2.9 \%$ of controls. Fortunately, low flow rates have been found to improve in a majority of patients by puberty. ${ }^{56} \mathrm{~A}$ recent review of 93 adults with hypospadias presenting to a reconstructive urologist highlight the long-term issues that can occur following childhood repairs, including lower urinary tract symptoms (55\%) and significant rate of urethral stricture (47\%), although there is a selection bias in this study. ${ }^{57}$ Long-term sexual issues, such as erectile dysfunction, ${ }^{58}$ ejaculatory difficulties, ${ }^{59}$ lower self-esteem, teasing, and negative genital perception, have been reported in patients with hypospadias. ${ }^{60,61}$ Several studies have found overall sexual function to be equivalent or slightly lower compared to controls..$^{53,62}$

There is very limited information on the long-term outcomes of uncorrected hypospadias. A study of 56 adults with primarily distal hypospadias showed that $5 \%$ expressed dissatisfaction with the appearance of their genitals and 32\% were unaware they had an anomaly. Over a third of these patients had voiding issues and $5 \%$ sat to void. This is in contrast to a study of adult men with hypospadias evaluated during transurethral surgery, who reported that they could void in a standing position and have sexual intercourse without problems. ${ }^{63}$

\section{Conclusion}

Hypospadias is a common genital condition in boys with varying severity and long-term functional implications. 
Keays et al.

Modern surgical techniques have significantly reduced complication rates, but standardization of reporting and well-designed prospective studies will further aid surgical decision-making. There is an increasing body of evidence suggesting that long-term followup and patient-reported outcome measures should form the key to assess surgical results.

Competing interests: The authors report no competing personal or financial interests.

This paper has been peer-reviewed.

\section{References}

1. Nelson CP, Park JM, Wan J, et al. The increasing incidence of congenital penile anomalies in the United States. J Urol 2005:174;1573-6. https://doi.org/10.1097/01.ju.0000179249.21944.7e

2. Schnack TH, Poulsen G, Myrup C, et al. Familial coaggregation of cryptorchidism and hypospadias. Epidemiology 2010;21:109-13. https://doi.org/10.1097/EDE.0b013e3181c15a50

3. Pieretti RV, Pieretti A, Pieretti-Vanmarcke R. Circumcised hypospadias. Pediat Surg Int 2009;25:53-5. https://doi.org/10.1007/s00383-008-2254-1

4. Snodgrass W, Khavari R. Prior circumcision does not complicate repair of hypospadias with an intact prepuce. J Urol 2006;176:296-8. https://doi.org/10.1016/50022-5347(06)00564-7

5. Kaefer $M$, Diamond $D$, Hendren WH, et al. The incidence of intersexuality in children with cryptorchidism and hypospadias: Stratification based on gonadal palpability and meatal location. J Urol 1999;163:1003-6. https://doi.org/10.1097/00005392-199909000-00010

6. McAlleer IM, Kaplan GW. Is routine karyotyping necessary in the evaluation of hypospadias and cryptorchidism? J Urol 2001;165:2029-31. https://doi.org/10.1016/50022-5347(05)66287-8

7. Cox MJ, Coplen DE, Austin PF. The incidence of disorders of sexual differentiation and chromosomal abnormalities or cryptorchidism and hypospadias stratified by meatal location. J Urol 2008; 180:2649-52. https://doi.org/10.1016/i.juro.2008.08.058

8. Snodgrass WT, Bush NC. Reoperative urethroplasty after failed hypospadias repair: How prior surgery impacts risk for additional complications. J Ped Urol 2016. Epub ahead of print.

9. Manzoni G, Bracka A, Palminteri E, et al. Hypospadias surgery: When, what, and by whom? BJU Int 2004;94:1188-95. https://doi.org/10.1046/i.1464-410x.2004.05128.x

10. Cimador M, Vallasciani S, Manzoni G, et al. Failed hypospadias in pediatric patients. Nat Rev2013;10:65765. https://doi.org/10.1038/nrurol.2013.164

11. Snodgrass W, Macedo A, Hoebeke P, et al. Hypospadias dilemmas: A round table. J Pediatr Urol 2011;7:145-57. https://doi.org/10.1016/i.jpurol.2010.11.009

12. Snodgrass $\mathrm{W}$, Cost N, Nakonezny PA, et al. Analysis of risk factors for glans dehiscence after tubularized incised plate hypospadias repair. J Urol 2011;185:1845-9. https://doi.org/10.1016/i. juro.2010.12.070

13. Steven $\mathrm{L}$, Cherian $\mathrm{A}$, Yankovic $\mathrm{F}$, et al. Current practice in pediatric hypospadias surgery: A specialist survey. J Pediatr Urol 2013; 9:1126-30. https://doi.org/10.1016/i.jpurol.2013.04.008

14. Springer A, Krois W, Horcher E. Trends in hypospadias surgery: Results of a worldwide survey. Eur Urol 2011;60:1184-9. https://doi.org/10.1016/i.eururo.2011.08.031

15. Gilliver SC, Ashworth J, Ashcroft GS. The hormonal regulation of cutaneous wound healing. Clin Dermatol 2007;25:56-62. https://doi.org/10.1016/i.clindermatol.2006.09.012

16. Gorduza DB, Gay CL, de Mattos E, et al. Does androgen stimulation prior to hypospadias surgery increase the rate of healing complications? A preliminary report. J Pediatr Urol 2011;7:158-61. https://doi.org/10.1016/i.jpurol.2010.05.003

17. Snodgrass W, Bush N. Primary hypospadias repair techniques: A review of the evidence. Urology Ann 2016;8;403-8. https://doi.org/10.4103/0974-7796.192097

18. Netto JMB, Ferrarez CEPF, Leal AAS, et al. Hormone therapy in hypospadias surgery: A systematic review. J Pediatr Urol 2013, 9:971-9. https://doi.org/10.1016/i.jpurol.2013.03.009

19. Malik RD, Liu DB. Survey of pediatric urologists on the preoperative use of testosterone in the surgical correction of hypospadias. J Pediatr Urol 2014;10:840-3. https://doi.org/10.1016/i.jpurol.2014.02.008

20. Mouriquand PDE, Gorduza DB, Noche M-E, et al. Long-term outcome of hypospadias surgery: Current dilemmas. Curr Opin Urol 2011;21:465-9. hitps://doi.org/10.1097/MOU.0b013e32834abda3

21. American Academy of Pediatrics. Timing of elective surgery on the genitalia of male children with particular reference to the risks, benefits, and psychological effects of surgery and anesthesia. Pediatrics 1996;97:590-4.
22. Yildiz $\mathrm{T}$, Tahtali IN, Ates $\mathrm{DC}$, et al. Age of patient is a risk factor for urethrocutaneous fistula in hypospadias surgery. J Pediatr Urol 2013;9: 900-3. https://doi.org/10.1016/i.jpurol.2012.12.007

23. Lu W, Tao $Y$, Wisniewski AB, et al. Different outcomes of hypospadias surgery between North America, Europe, and China: Is patient age a factor? Neuphrourol Mon 2012;4:609-12. https://doi.org/10.5812/numonthly. 1853

24. Chalmers DJ, Siparkky GL, Wiedel CA, et al. Distal hypospadias repair in infants without a postoperative stent. Pediatr Surg Int 2015;31:287-90. hitps://doi.org/10.1007/s00383-014-3647-y

25. Mclorie $G$, Joyner $B$, Herz $D$, et al. A prospective randomized clinical trial to evaluate methods of postoperative care of hypospadias. J Urol 2001;165:1669-72. https://doi.org/10.1016/S0022$5347(05) 66388-4$

26. Zeiai S, Nordenskjold A, Fossum M. Advantages of reduced prophylaxis after tubularized incised plate repair of hypospadias. J Urol 2016;196:1244-9. hittps://doi.org/10.1016/i.juro.2016.04.083

27. Baillargeon E, Duan K, Brzezinski $A$, et al. The role of preoperative prophylactic antibiotics in hypospadias repair. Can Urol Assoc J 2014;8:236-40. https://doi.org/10.5489/cuaj.1838

28. Braga LH, Jegatheeswaran K, MCGrath M et al. Cause and effect vs. confounding: Is there a true association between caudal blocks and tubularized incised plate repair complications? I Urol 2016. [Epub ahead of print]. https://doi.org/10.1016/i.juro.2016.08.110

29. Mingin G, Baskin LS. Management of chordee in children and young adults. Urol Clin North Am 2002; 29:277-84. https://doi.org/10.1016/S0094-0143(02)00044-7

30. Kraft KH, Shukla AR, Canning DA. Proximal hypospadias. ScientificWorldJournal 2011;11 894-906. https://doi.org/10.1100/tsw.2011.76

31. Belman BA:. Re: outcome analysis of severe chordee correction using tunica vaginalis as a flap in boys with proximal hypospadias. J Urol 2007;178:1697. https://doi.org/10.1016/i. juro.2007.03.399

32. Braga LHP, Pippi Salle JL, Dave S, et al. Outcome analysis of severe chordee correction using tunica vaginalis as a flap in boys with proximal hypospadias. J Urol 2007;178:1693-7. https://doi.org/10.1016/i. juro.2007.03.166

33. Braga LH, Lorenzo AJ, Bagli DJ. Ventral penile lengthening versus dorsal plication for severe ventral curvature in children with proximal hypospadias. J Urol 2008;180:1743-7. htrps://doi.org/10.1016/i. juro.2008.03.087

34. Dason S, Wong N, Braga LH. The contemporary role of 1 vs. 2-stage repair for proximal hypospadias. Transl Androl Urol 2014;3:347-58.

35. Decter RM, Franzoni DF. Distal hypospadias repair by the modified Thiersh-Duplay technique with or without hinging the urethral plate: a near ideal way to correct distal hypospadias. J Urol 1999; 162:1156-8. https://doi.org/10.1016/S0022-5347(01)68109-6

36. Zaontz MR. The GAP (glans approximation procedure) for glanular/coronal hypospadias. J Urol 1989;141:359-61

37. Snodgrass W. Tubularized, incised plate urethroplasty for distal hypospadias. J Urol 1994;151:464-5.

38. Steven L, Cherian A, Yankovic F, et al. Current practice in pediatric hypospadias surgery: A specialist survey. J Pediatr Urol 2013;9:1126-30. https://doi.org/10.1016/i.jpurol.2013.04.008

39. Koff SA. Mobilization of the urethra in the surgical treatment of hypospadias. J Urol 1981;125: 394-7.

40. Hassan HS, Almetaher HA, Negm M, et al. Urethral mobilization and advancement for distal hypospadias. Ann Pediatr Surg 2015;11:239-43. https://doi.org/10.1097/01.XPS.0000472853.75905.28

41. Nguyen MT, Snodgrass WT, Zaontz MR. Effect of urethral plate characteristics on tubularized incised plate. J Urol 2004;171:1260-2. hrtps://doi.org/10.1097/01.ju.0000110426.32005.91

42. Gundeti M, Queteishat A, Desai $D$, et al. Use of an inner preputial free graft to extend the indications of Snodgrass hypospadias repair (Snodgraft). J Pediatr Urol 2005;1:395-6. https://doi.org/10.1016/i. jpurol.2005.03.010

43. Mathieu P. Traitement en un temps de l'hypospadias balanique ou juxtabalanique. J Chir 1932; 39:481.

44. Asopa HS, Elhence IP, Atri SP, et al. One-stage correction of penile hypospadias using a foreskin tube: A preliminary report. Int Surg 1971;55:435-40.

45. Duckett JW. The island flap technique for hypospadias repair. Urol Clin North Am1981; 8:503-11.

46. Ververidis M, Dickson AP, Gough DC. An objective assessment of the results of hypospadias surgery. BJU Int 2005;96:135-9. https://doi.org/10.1111/j.1464-410X.2005.05582.x

47. Scarpa M, Castagnetti M, Musi L, et al. Is objective assessment of cosmetic results after distal hypospadias repair superior to subjective assessment? J Pediatr Urol 2009;5:110-3. https://doi.org/10.1016/i. jpurol.2008.10.004

48. Snodgrass WT, Bush N, Cost N. Tubularized incised plate hypospadias repair for distal hypospadias. J Pediatr Urol 2010;6:408-13. https://doi.org/10.1016/i.jpurol.2009.09.010

49. Wilkinson DJ, Farrelly P, Kenny SE. Outcomes in distal hypospadias: A systematic review of the Mathieu and tubularized incised plate repairs. J Pediatr Urol 2012;8:307-12. https://doi.org/10.1016/i. ipurol.2010.11.008

50. Castagnetti $M$, El-Ghoneimi A. Surgical management of primary severe hypospadias in children: Systematic 20-year review. J Urol 2010;184:1469-74. htrps://doi.org/10.1016/i.juro.2010.06.044 
51. Long CJ, Chu DI, Tenney RW, et al. Intermediate-term followup of proximal hypospadias reveals high complication rate. J Urol 2016; 16:31748-7. [Epub ahead of print]. https://doi.org/10.1016/i. juro.2016.11.054

52. Xiao D, Nie X, Wang W, et al. Comparison of transverse island flap onlay and tubularized incised-plate urethroplasties for primary proximal hypospadias: A systematic review and meta-analysis. PLoS One 2014;9:e106917. https://doi.org/10.1371/journal.pone.0106917

53. Sugita Y, Tanikaze $S$, Yoshino K, et al. Severe hypospadias repair with meatal based paracoronal skin falp: The modified Koyanagi repair. J Urol 2001;166:1051-3. https://doi.org/10.1016/S0022$5347(05) 65918-6$

54. Mousavi SA, Aarabi M. Tubularized incised plate urethroplasty for hypospadias reoperation: A review and meta-analysis. Int Braz J Urol 2014;40:588-95. https://doi.org/10.1590/S1677-5538. IBJU.2014.05.02

55. Rynia SP, de Jong TP, Bosch JL, et al. Functional, cosmetic and psychosexual results in adult men who underwent hypospadias correction in childhood. J Pediatr Urol 2011;7:504-15. https://doi.org/10.1016/i.jpurol.2011.02.008

56. Hueber P-A, Antczak C, Abdo A, et al. Long-term functional outcomes of distal hypospadias repair: A singlecentre, retrospective comparative study of TIPS, Mathieu, and MAGPI. J Pediatr Urol 2015;11:68e 1-7.

57. Hoy NY, Rourke KF. Befter defining the spectrum of adult hypospadias: Examining the effect of childhood surgery on adult presentation. Urology 2016;16:30628-8 [Epub ahead of print]. https://doi.org/10.1016/i.urology.2016.07.057
58. Svensson J, Berg G. Operated hypospadiacs: Late followup. Social, sexual, and psychological adaptation. J Pediatrc Surg 1981;16:134-5. https://doi.org/10.1016/S0022-3468(81)80338-7

59. Kumar S, Tomar V, Yadav SS, et al. Fertility potential in adult hypospadias. J Clinc Diagn Res. J Urol 2016;10:PC01-5.

60. Vandendriessche $S$, Baeyens $D$, Van Hoecke $E$, et al. Body image and sexuality in adolescents after hypospadias surgery. J Ped Urol 2010; 6:54-9.

61. Keays MA, Starke N, Lee SC, et al. Patient reported outcomes in preoperative and postoperative patients with hypospadias. J Urol 2016;195:1215-20. https://doi.org/10.1016/i.juro.2015.11.066

62. Ruppen-Greeff NK, Weber DM, Gobet $R$, et al. Health-related quality of life in men with corrected hypospadias: An explorative study. J Ped Urol 2013;9:551-8. https://doi.org/10.1016/i.jpurol.2013.04.016

63. Fichtner J, Filipas D, Mottrie AM, et al. Analysis of meatal location in 500 men: Wide variation questions need for meatal advancement in all pediatric anterior hypospadias cases. J Urol 1995; 154:833-4. https://doi.org/10.1016/S0022-5347(01)67177-5

Correspondence: Dr. Melise A. Keays, Division of Urology, Department of Surgery, Children's Hospital of Eastern Ontario, University of Ottawa, Ottawa, ON, Canada; MKeays@cheo.on.ca 